\title{
EPSL
}

Earth and Planetary Science Letters 141 (1996) 21-33

\section{The Bauer scarp ridge jump: a complex tectonic sequence revealed in satellite altimetry}

\author{
John A. Goff ${ }^{\text {a, * }}$, James R. Cochran ${ }^{\text {b }}$ \\ ${ }^{a}$ Institute for Geophysics, University of Texas at Austin, 8701 N. MoPac Expy, Austin, TX 78759, USA \\ b Lamont-Doherty Earth Observatory, Palisades, NY 10964, USA
}

Received 25 September 1995; accepted 22 March 1996

\begin{abstract}
We investigate here the ridge jump that led to abandonment of the Galapagos Rise and formation of the Bauer scarp during the initiation of the present day configuration of the East Pacific Rise since the lower Miocene. We use recently available high resolution satellite-derived gravity data to investigate in detail the tectonic structure of the eastern Pacific from the Equator to $20^{\circ} \mathrm{S}$. With this data, we identify fracture zones, abandoned spreading ridges, scarps, and other seafloor features that provide evidence for discerning tectonic history.

Based on our structural interpretation of the satellite-derived gravity field, we make the following conclusions: (1) The Galapagos Rise spreading center appears to have originated by opening of the Marquesas/Mendaña transform complex as a result of the change in spreading direction following breakup of the Farallon Plate. (2) The Galapagos Rise was not the sole locus of spreading following plate reorganization at $\sim 20 \mathrm{Ma}$ through to the initiation of the Bauer scarp at $\sim 8 \mathrm{Ma}$, as had been previously hypothesized. Rather, it and a second western spreading axis were likely active concurrently, forming a counterclockwise-rotating Bauer Microplate at a much earlier stage than thought previously. (3) The Bauer scarps are pseudofaults associated with northward rift propagation. Propagation proceeded in several stages. A first propagator emanating from the Garrett transform complex stalled at the future location of the Wilkes transform creating an area of complex morphology near its northern tip. A second propagator, also emanating from the Garrett complex followed in the first's wake and broke through the complex region. At this point the propagation proceeded very rapidly to the northern end of the Bauer Microplate (the Gallego fracture zone, later to become the Yaquina transform fault). Ridge propagation continued north in two more stages, creating the Gofar and Quebrada transforms at the terminus of each stage.
\end{abstract}

Keywords: East Pacific Rise; spreading centers; gravity surveys; satellite methods

\section{Introduction}

Mid-ocean ridges and transform faults reorganize in response to changes in plate motion. Small changes generally lead to reorientation of transform faults

\footnotetext{
${ }^{*}$ Corresponding author. Fax: +1 512471 8844. E-mail: goff@utig.ig.utexas.cdu
}

and ridge axes, often accommodated through the mechanism of ridge propagation [1-3]. Larger changes in plate motion can, however, cause a more drastic response: the abandonment of one spreading ridge and formation of a new one, either through ridge propagation or coincident initiation of rifting along the length of the new axis. We apply the term 'ridge jumps' to differentiate such events from more 
common ridge reorganization and propagation. The difference is largely a matter of scale, but the discriminating factor is the presence of a fossil ridge. The most recent and best-documented ridge jumps include abandonment of spreading along the Mathematician Rise at $\sim 5 \mathrm{Ma}[4,5]$ and along the Galapagos Rise at $\sim 8-6 \mathrm{Ma}$ (Fig. 1) [3,5-9]. In both cases, the primary locus of spreading was transferred hundreds of kilometers, creating the current East Pacific Rise (EPR) axis configuration.

Ridge jumps are an important mechanism by which major plate boundary reorganizations are accommodated. Much of the present southern EPR (Pacific-Nazca plate boundary) was formed by a series of ridge jumps apparently initiated by a $20-30^{\circ}$ rotation in spreading direction following the breakup of the Farallon Plate $[3,10,11]$. In addition to the Galapagos Rise, abandoned spreading centers imbedded in the Nazca Plate include the Mendoza and Roggeveen rises [11,12]. Together, these features form a continuous fossil spreading center extending from the Gofar fracture zone, near $5^{\circ} \mathrm{S}$, at least to the Challenger fracture zone, near $35^{\circ} \mathrm{S}$. The Selkirk Trough, south of the Challenger fracture zone, also appears to result from a ridge jump, with the transferred lithosphere now embedded in the Pacific Plate [13]. It has also been demonstrated [13,14] that the Pacific-Antarctic-Nazca triple junction has mi- grated northward in a series of ridge jumps which transferred large sections of Nazca Plate lithosphere to the Antarctic Plate. Thus, much of the evolution and present plate boundary geometry of the eastern Pacific is a direct result of ridge jumps.

The principal evidence documenting ridge jumps consists of the existence of the fossil rises, symmetric magnetic anomalies centered on the fossil rises, and the scarps associated with the subsequent breakup of the oceanic plate to form a new spreading axis. During a ridge jump it is hypothesized that both the newly formed and dying rifts spread simultaneously for a time, forming a large, short lived microplate $[3,4]$. This hypothesis suggests that the currently active Easter (e.g. [15,16]) and Juan Fernandez (e.g. $[17,18])$ microplates are not adequate modern analogs for ridge jump-created microplates. The modern microplates began as small features and have grown steadily for at least $4 \mathrm{~m} . \mathrm{y}$. to much larger features (but $\leq \sim 400 \mathrm{~km}$ ), whereas the ridge jump microplates presumably began as large features $(>400$ $\mathrm{km}$ ) and appear transitory (active for $\sim 2 \mathrm{Ma}[3]$ ). As a result, the interiors of fossil ridge jump microplates are thought to consist primarily of transferred lithosphere, while the interiors of the active Easter and Juan Fernandez microplates consist primarily of lithosphere created during the evolution and growth of the microplate. However, as shall be

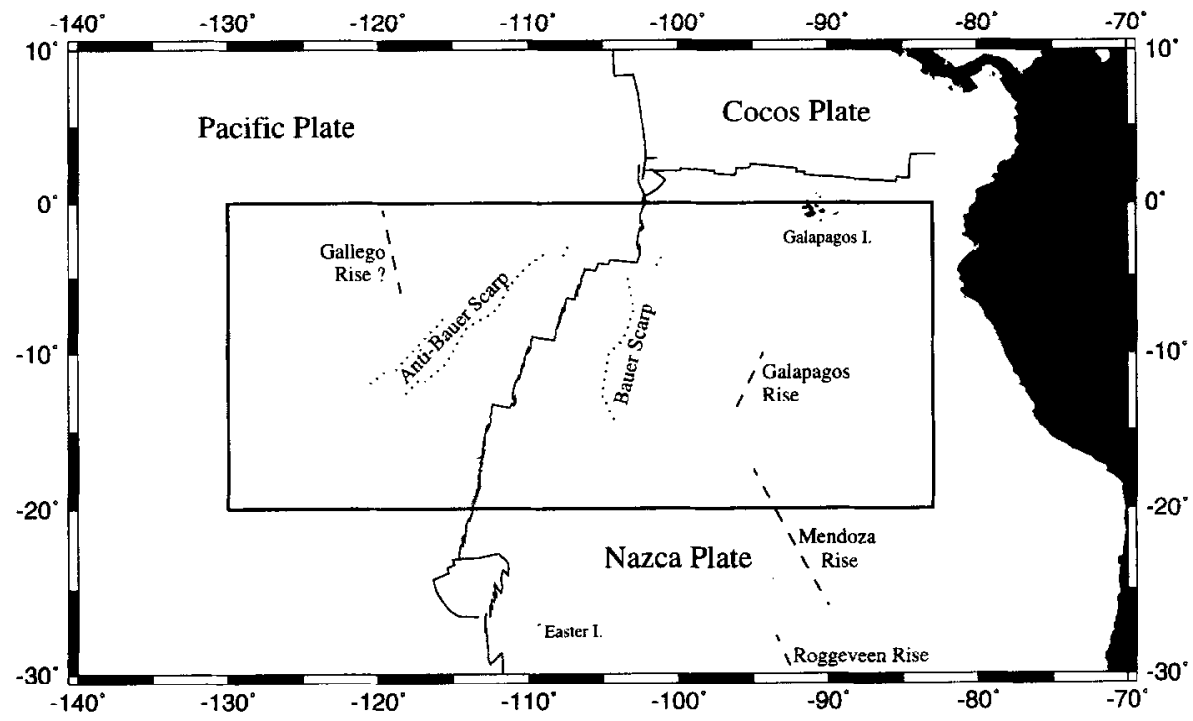

Fig. 1. Tectonic setting of the Bauer scarp ridge jump. Box outlines area shown in Fig. 2 and Fig. 3. 
demonstrated in this paper, previous hypotheses for the formation of the Bauer Microplate are probably incorrect, and these assumptions will need to be re-examined.

In spite of their importance as an agent of plate boundary reorganization and the prominent role which they have played in the geologic evolution of the eastern Pacific since the late Oligocene, ridge jumps are a little studied and not well understood phenomenon. While changes in plate motion are generally identified as the instigator of ridge jumps $[3,4,8]$, very little is known about the mechanism of formation of the new rift or how the ridge-transform geometry of the new spreading center is established and evolves. A major factor inhibiting the analysis and understanding of features associated with ridge jumps is simply the lack of data. The available morphological data primarily consist of scattered and often serendipitous track lines of wide-beam echo sounder data, usually on transits to and from the East Pacific Rise.

Recent availability of high resolution satellite altimetry-derived gravity data [19] provides us with unprecedented opportunities for exploring the structure of wide tracts of the ocean floor. Large seafloor features associated with ridge jump events (i.e., fracture zones, active and fossil rises, and large scarps) are usually discernible in the new altimetry data. In this paper we use a joint ERS-1, Topex and Geosat altimetry data grid [19] to investigate tectonic events leading up to and including the ridge jump that led to abandonment of the Galapagos Rise and formation of the Bauer scarps (Fig. 1). Here we refer to the east scarp as the Bauer scarp, the west scarp as the Anti-Bauer scarp, and both jointly as the Bauer scarps. We find that none of the hypothesized tectonic histories $[3,6,8]$ can account for all of the principal observed structures. We find it necessary to postulate a far more complex tectonic history than considered previously. The most controversial component of this hypothesis may be the assertion that, following plate reorganization at $\sim 20 \mathrm{Ma}$, both the Galapagos Rise and another spreading axis to the west of it were active concurrently, forming a relatively long-lived, counterclockwise rotating Bauer Microplate well before formation of the Bauer scarps and initiation of EPR spreading. The Bauer Microplate may have been active and stable for more than 10 m.y. The Bauer scarps were then generated in a complex sequence of northward ridge propagation stages, involving both slow and fast propagation, with the western axis, rather than the Galapagos Rise, acting as failing rift. The formation of the Bauer scarps were followed closely by capture of full spreading by the current EPR axis and abandonment of the Galapagos Rise. The formation of new transform faults are generally associated with the termination of rift propagation stages.

\section{Previous hypotheses for the Bauer scarp ridge jump}

The Bauer scarp and conjugate Anti-Bauer scarp (Fig. 1) were the site of a ridge jump event which occurred from $\sim 8 \mathrm{Ma}$ to $\sim 6 \mathrm{Ma}[3,6]$. This is the youngest of the series of ridge jumps by which the modern southern EPR was created, as the result of the reorganization in spreading following the breakup of the Farallon Plate into the Nazca and Cocos plates. The generally accepted hypothesis for the sequence of events leading up to and including the Bauer ridge jump is presented in Mammerickx et al. [6]. We summarize this previous hypothesis as follows: The events begin with the major clockwise reorganization of the direction of spreading along the EPR that occurred at $\sim 20 \mathrm{Ma}$. Following reorganization, all Pacific-Nazca spreading between $\sim 5^{\circ} \mathrm{S}$ and $\sim 15^{\circ} \mathrm{S}$ occurred along the Galapagos Rise, bounded north and south by large transforms that had taken the place of those that had formed the Galapagos and Marquesas fracture zones to the west and the Grijalva and Mendaña fracture zones to the east. Galapagos Rise spreading continued for $\sim 10$ m.y., at which point the Bauer ridge jump transferred the locus of Pacific-Nazca spreading westward to the current EPR axis $[7,8,11,12]$, creating new transform faults (Garrett, Wilkes, Yaquina, Gofar and Quebrada) in the process. The new rift, which became the present EPR axis, formed in lithosphere $\sim$ 10-13 m.y. old and, as a result, a band of Pacific Plate lithosphere approximately $700-900 \mathrm{~km}$ wide was transferred to the Nazca Plate. For a brief while $(\sim 2$ m.y), however, both axes were active $[3,6]$, forming a Bauer Microplate [3].

Two other hypotheses presented in the literature 


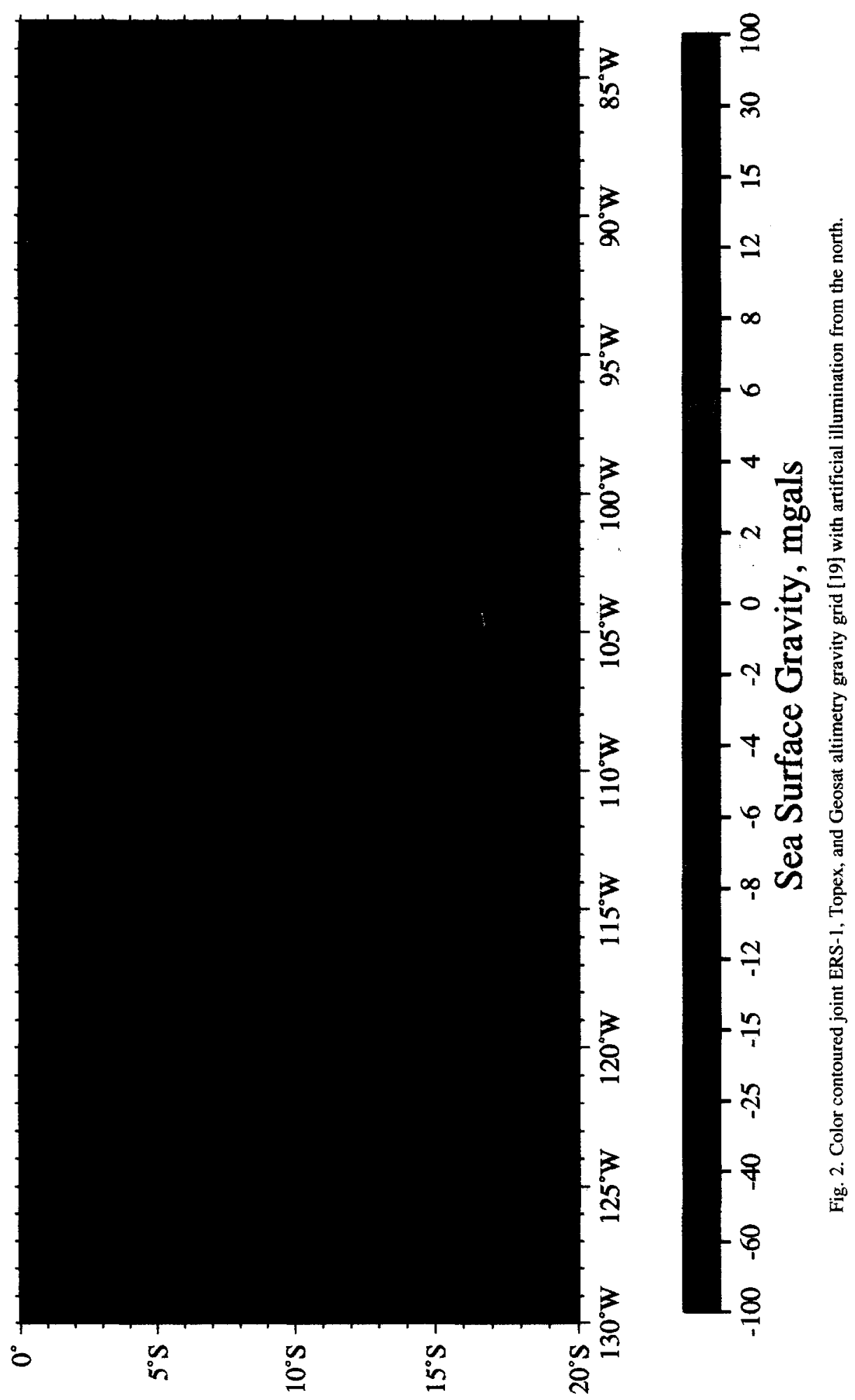


address specific details associated with the formation of the Bauer scarps. Rea [8] postulated a step-wise northward progression of the ridge jump on the basis of the parallelism between the Bauer scarp and the current ridge axis, and the step-wise decrease northward in the distance between the ridge axis and the scarp across each fracture zone. In this scenario, each step in the northward progression is bounded north and south by the current fracture zone locations. Rea [8] noted that the Bauer scarp is nearly collinear across the eastward extensions of the Wilkes and Yaquina fracture zones, implying that the present ridge-transform configuration did not form concurrently with the scarp. Hence, each new northward step must occur at precisely the correct time to maintain an approximately collinear scarp to the east. Rea [8] noted that this collinearity could hardly be mere coincidence, and proposed that there is a preference for segments of the new rise to begin along the same trend at different times, perhaps as a result of a pre-existing linear zone of incipient asthenospheric melt. Note that this hypothesis requires that each present EPR fracture zone existed for a time as a very large-offset left-lateral transform between the dying Galapagos Rise and the newly forming EPR axis to the west.

Lonsdale [3] formulated an alternative hypothesis to Rea [8] based on Mammerickx et al.'s [4] description of the Mathematician paleoplate and observations of the Easter Microplate [20]. He proposed that the transfer of spreading from the Galapagos Rise to the current EPR axis occurred by means of a propagating rift, temporarily creating a Bauer Microplate between the two spreading axes. Under this scenario, the Wilkes transform fault developed when the Dana transform (a paleo-transform on the Galapagos Rise system at approximately the same latitude as Wilkes) marked the temporary boundary between failed and failing segments of the Galapagos Rise, creating a lateral differential in spreading rate on the EPR, resulting in creation of the Wilkes transform. In Lonsdale's model, no transform motion between the Galapagos Rise and EPR axis ever existed, and the Bauer and Anti-Bauer scarps represent a pseudofault wake of the northward-propagating axis.

\section{Altimetry data and structural interpretation}

The hypotheses of Mammerickx et al. [6], Rea [8] and Lonsdale [3] were based primarily on widely spaced ship tracks using single-beam echo sounders. With the benefit of hindsight, we know that these data are insufficient to identify and characterize

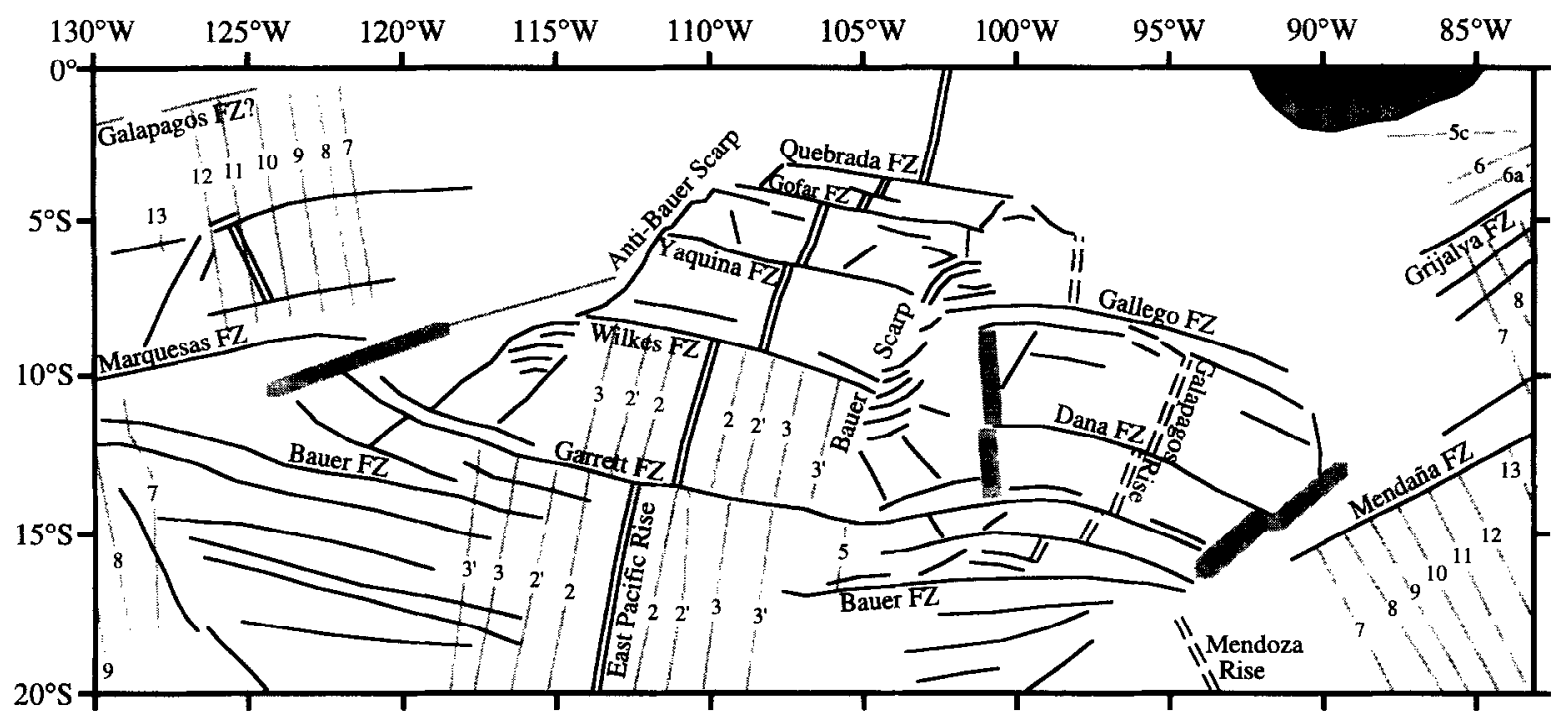

Fig. 3. Structural interpretation based on the data presented in Fig. 2. Magnitic anomaly picks from [23] are also shown with light gray lines. Identification of the Galapagos fracture zone is considered very tenuous. 
1: $-20 \mathrm{Ma}$

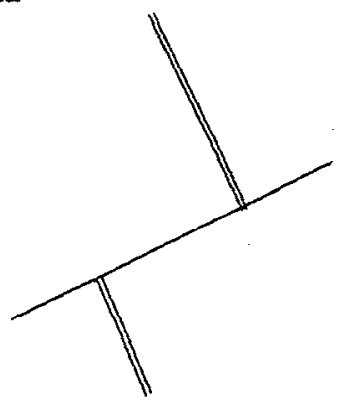

3: $\sim 8 \mathrm{Ma}$

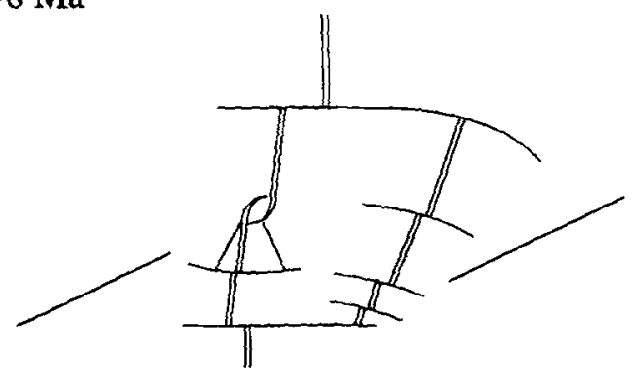

2: $\sim 17 \mathrm{Ma}$

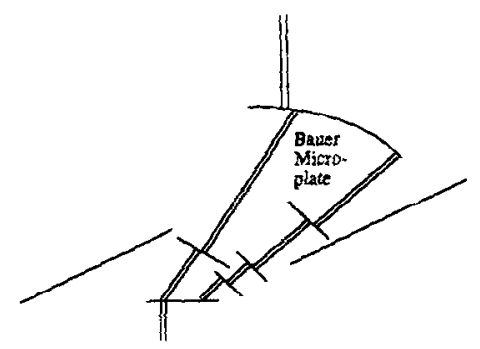

4

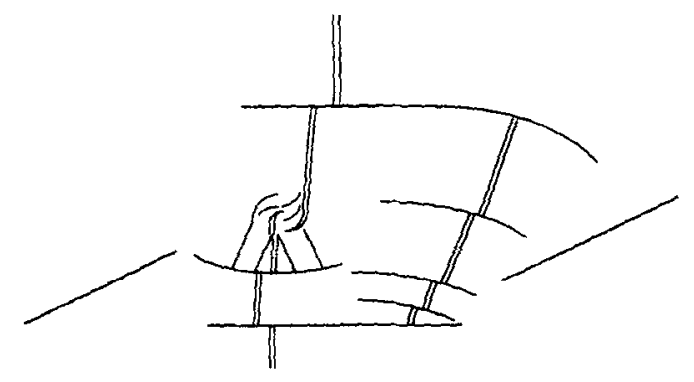

5

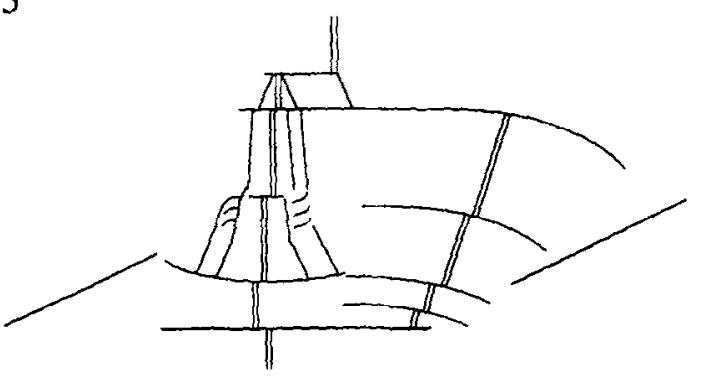

6: $\sim 6 \mathrm{Ma}$

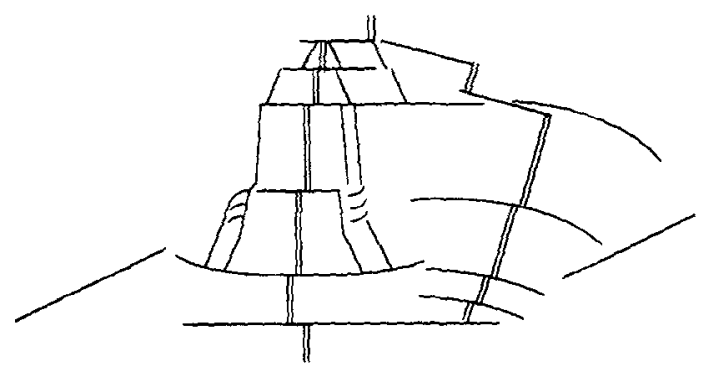

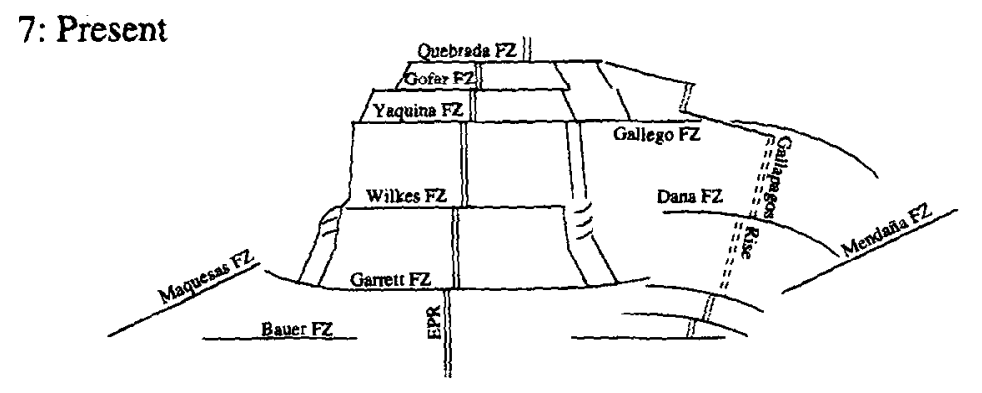


properly most of the principal structures associated with the Bauer ridge jump event. The coverage (from $\sim 20^{\circ} \mathrm{S}$ to the Equator, and from $\sim 130^{\circ} \mathrm{W}$ to $\sim$ $80^{\circ} \mathrm{W}$ ) needed is far too large for any acoustic mapping program to identify pre-20 Ma fracture zones and all structures which were created from then until the present. Gravity anomalies derived from satellite altimetry, which are highly correlated to seafloor topography at scales larger than $\sim 25 \mathrm{~km}$ [21] and less than $\sim 800 \mathrm{~km} \mathrm{[22]} \mathrm{provide} \mathrm{us} \mathrm{with} \mathrm{the}$ necessary coverage. The resolution of earlier public domain releases of altimetry data sets was insufficient to identify most of the features of interest in this study. However, the recent public release of a joint ERS-1, Topex and Geosat data set including recently declassified Geosat data north of $30^{\circ} \mathrm{S}$ [19] does provide sufficient clarity to identify principal structures.

A color contoured, sun-illuminated image of the satellite gravity grid in the eastern central Pacific is shown in Fig. 2. A structural interpretation is provided in Fig. 3, along with available magnetic anomaly picks [23]. There are several important new observations evident in these figures:

(1) The fracture zones associated with the Galapagos Rise (Gallego, Dana, eastward extension of the Garrett, and an unnamed fracture zone) are curved. especially the previously unnamed Gallego fracture zone at the north end of the rise. These tightly curved fracture zones (concave down) indicate that spreading along the Galapagos Rise was associated with a nearby pole of rotation to the south (located approximately at $98^{\circ} \mathrm{W}, 27^{\circ} \mathrm{S}$ ); that is, one that would not be consistent with Pacific-Nazca spreading but, rather, requires a rotating microplate. We use the name 'Gallego' for the transform at the northern boundary of the Bauer Microplate after the Gallego Rise (Fig. 1), an apparent fossil spreading ridge identified by Mammerickx et al. [6] at $\sim 120^{\circ} \mathrm{W}$ between the Marquesas and Galapagos fracture zones. However, this fossil ridge axis is not evident in the satellite gravity (Fig. 2) or on the few shipboard profiles available to us, and in our model (Fig. 4) that section of ridge axis was reactivated to form the proto-Gallego transform.

(2) The Garrett fracture zone in the vicinity of both Bauer scarps and toward older crust is also curved, but in the opposite sense (concave up) from the Galapagos Rise fracture zones. This is consistent with the existence of a spreading axis west of the Galapagos Rise with its spreading rate increasing to the south, which acted as the conjugate side of a counterclockwise-rotating microplate. The curvature on the Garrett ceases on crust younger than the Bauer scarps, indicating that microplate rotation also ceased at this time.

(3) The Bauer and Anti-Bauer scarps generally decrease in distance from each other from south to north, indicating a northward propagating rift system (consistent with the hypothesis of Lonsdale [3]). The details of this propagation are very complex, however. Two propagators appear to have originated from the Garrett transform complex. The first, a slow propagation event (this and subsequently described 'slow' propagation events propagated at roughly 100 $\mathrm{km} / \mathrm{my}$, assuming current spreading rates apply), appears to have stalled at the location of the future Wilkes fracture zone and perhaps formed a large overlapping spreading system. Several curved lineaments are found in the northern part of the wake of this stalled propagator on both the Bauer and AntiBauer sides. The origin of these features is uncertain. Possible explanations include duelling propagators [24], tightly spaced transform offsets, a distributed shear zone or Pito Deep-like rifts [25], although none of these appear to explain the observed morphology adequately. A second, slow propagator also originated from the Garrett transform complex. When it reached the area of the curved lineations, it accelerated and propagated rapidly $(\sim 600 \mathrm{~km} / \mathrm{my}$, assuming current spreading rates apply) through them all the way to the Gallego fracture zone. This phase of propagation included a right-stepping kink at what became the right-lateral Wilkes transform complex. The Yaquina transform formed at the Gallego fracture zone. A slower pace of northward propagation 
ensued closely thereafter, ending with the creation of the Gofar transform. Another short stage of propagation offset to the east ended in the formation of the Quebrada transform.

We also note that the initial stages of propagation appear to emanate from the Garrett transform without eliminating it. The propagation from the Gofar to the Quebrada transforms likewise did not eliminate the Gofar transform. These observations are not unprecedented. For example, Bird and Naar [26] conclude that both the Easter and Juan Fernandez microplates initiated from propagating ridges originating from within transform faults. It is likely in these cases that the transforms consist of multiple offsets (as is seen along many active EPR transform complexes [27-29]) and that individual offsets can propagate away without removing the entire transform complex.

(4) With the exception of regions just south of the Wilkes fracture zone, the Anti-Bauer scarp is generally a sharp, well-defined feature, whereas the Bauer scarp is complex, composed of numerous en echelon curved lineaments. This sort of dichotomy between pseudofaults is consistent with a failed rift to the east of a northward-propagating ridge [20,30,31]. If the Bauer scarps represent a failed rift pseudofault, then, clearly, an additional rift west of the Galapagos Rise must have existed prior to formation of the Bauer scarp.

(5) Regions of disturbed morphology (gravity) are located at approximately the same distance on either side of the Galapagos Rise axis (Fig. 3). We suggest that these disturbed zones mark the initiation of rifting along the Galapagos Rise. The eastern disturbed zone lies subparallel to and along the northern edge of the Mendaña fracture zone. The breakup of the Farallon Plate into the present Cocos and Nazca plates occurred in the lower Miocene when the Grijalva fracture zone opened up to become a spreading center linking the proto-EPR to the Peru-Chile trench $[32,33]$. The Marquesas/Mendaña was the next major transform south of the Grijalva on the proto-EPR and was an extremely large-offset right-stepping transform. Handshumacher [11] measured Anomaly 7 ( 25 Ma) offsets of $883 \mathrm{~km}$ and $889 \mathrm{~km}$ across the Marquesas and Mendaña fracture zones, respectively. The total length of the Galapagos Rise axis and of the two disturbed zones is also between 800 and $900 \mathrm{~km}$. It thus appears probable that, at the time when spreading began across the Grijalva fracture zone, the Marquesas/Mendaña also began to open, with the ridge axis segment between the two fracture zones transformed into the proto-Gallego transform.

Another roughly linear region of disturbed morphology (gravity) is located between the westward terminus of the Garrett fracture zone and the eastward terminus of the Marquesas fracture zone (Fig. 3 ). This region stretches in a $\sim$ ENE direction, subparallel to the Marquesas fracture zone. A subtle lineament also continues $\sim$ ENE from that disturbed zone, intersecting the Anti-Bauer scarp north of the Wilkes fracture zone (Fig. 3). We suggest that this disturbed zone and lineament may mark the initiation of spreading along the western rift of the Bauer Microplate, forming soon after plate reorganization at $\sim 20 \mathrm{Ma}$.

(6) The Bauer fracture zone on the east flank of the EPR is accompanied by strong parallel gravity lineaments on its northern side, especially in the vicinity of $105^{\circ} \mathrm{W}$. These structures may be associated with a zone of compression, which is both expected [34] and observed [15,16,18,35-38] in rotating microplate systems. The location of these lineaments is consistent with a counterclockwise-rotating system [34].

\section{Comparison with previous hypotheses}

The structural interpretation presented in Fig. 3 provides strong contradictions for certain aspects of each of the hypotheses presented by Mammerickx et al. [6], Rea [8] and Lonsdale [3].

\subsection{Mammerickx's hypothesis}

A central component of the Mammerickx et al. [6] hypothesis (and subsumed in the Rea [8] and Lonsdale [3] hypotheses) is that, following reorganization of the EPR at $\sim 20 \mathrm{Ma}$, the Galapagos Rise accommodated full spreading between the Nazca and $\mathrm{Pa}$ cific plates up until the Bauer ridge jump at $\sim 8-6$ Ma. One problem with this component of the hypothesis is that the Galapagos Rise is located too far to the east. The location of the Mendaña and Marquesas fracture zones and the point at which these 
broke apart at EPR reorganization is well defined in Figs. 2 and 3. Removing from consideration the region lying between the Bauer and Anti-Bauer scarps, we find that the distance west from the Galapagos Rise to the Marquesas fracture zone is almost 2.5 times longer than the distance east from the Galapagos Rise to the Mendaña fracture zone $(1200 \mathrm{~km}$ vs. $500 \mathrm{~km}$ along the trace of the Dana fracture zone). For the Galapagos Rise to have accommodated the creation of all this lithosphere, we would have to postulate a large asymmetry in spreading. While spreading asymmetries as high as 5:1 have been observed [39], these instances are rare, and likely attributed to multiple propagation events. Given the stability of the transforms along the Galapagos Rise, we consider this unlikely. This is our first indirect evidence that some portion of spreading during the period immediately following reorganization might have occurred on a previously unrecognized spreading axis to the west of the Galapagos Rise.

\subsection{Rea's hypothesis}

Rea's [8] hypothesis for the step-wise formation of the Bauer scarp predicts: (1) that all current fracture zones extend past the Baucr scarp to connect up with Galapagos Rise fracture zones; and (2) that the Bauer scarp is continuous across fracture zones, while the Anti-Bauer scarp is offset at each fracture zone by an amount equal to twice the transform offset. Both of these predictions are clearly contradicted at the Wilkes and Yaquina fracture zones. An offset in the Anti-Bauer scarp does exist at the Gofar fracture zone. However, there is also an offset at this point in the Bauer scarp and the total distance between the scarps north of the Gofar fracture zone is nearly identical to the distance between the scarps immediately to the south of the Gofar fracture zone. Hence, it does not appear as if the rifting paused for a time at the Gofar fracture zone, but simply shifted immediately to the east, propagating northward from within the transform fault.

\subsection{Lonsdale's hypothesis}

Lonsdale [3] postulated that a Bauer Microplate existed for a short time (perhaps as long as 2 m.y.) after the formation of the Bauer scarp and modern EPR axis, and before the Galapagos Rise fully ceased to spread. The tightly curved Galapagos Rise fracture zones and the oppositely curved Garrett fracture zone give strong support to the existence of the Bauer Microplate. However, one piece of evidence strongly suggests that the Bauer Microplate formed far earlier than suggested by Lonsdale [3]: the Galapagos Rise fracture zones extend far eastward into the Nazca Plate on a downward-concave path, nearly to the Mendaña fracture zone. Likewise, the westward end of the Garrett fracture zone, although less clear in the gravity data, extends in a concave-up path nearly to the Marquesas fracture zone. This implies that the Bauer Microplate, with the Galapagos Rise serving as a Nazca-Bauer boundary and another spreading axis serving as the Pacific-Bauer boundary, was formed shortly after the $\sim 20 \mathrm{Ma}$ reorganization. This constitutes our second indirect evidence for a previously unrecognized spreading axis west of the Galapagos Rise. We also note that the curvature on the Garrett ceases following the formation of the Bauer scarps, indicating that this event signalled the end of microplate rotation.

The southern trace of the double Gallego fracture zone appears to be cross-cut, with little or no offset, by a linear feature emanating from the northern end of the Galapagos Rise (Figs. 2 and 3). The northern trace of the Gallego may also be cross-cut, but this is not clear in the gravity data. This feature appears to connect up the Galapagos Rise to another possible fossil rise to the northwest. The northern end of this additional fossil rise appears to be connected by structural lineaments to the Quebrada and/or Gofar fracture zone. However, these connecting lineaments do not represent long-lived fracture zones, as evidenced by the lack of significant eastward extension. We therefore suggest that these structures represent a very late stage restructuring of Galapagos Rise spreading, perhaps in response to the formation of the Bauer scar and initiation of spreading along the modern day EPR axis. This scenario is very similar to Lonsdale's [3] hypothesis for the way in which the Bauer Microplate was formed. We, instead, suggest that this event constituted a late-stage restructuring of the Bauer Microplate, which was already in existence.

Lonsdale [3] also postulated that the Bauer scarps 
formed by rift propagation, and therefore represent pseudofaults. As stated above, this hypothesis appears correct, although the details, consisting of several separate stages of propagation as described, are more complicated than envisioned by Lonsdale [3]. Also, as stated above, the difference in morphology between the Bauer and Anti-Bauer scarps strongly suggests that the Bauer scarp represents a failed rift pseudofault. This is the third piece of evidence for the existence of another rift west of the Galapagos Rise prior to formation of the Bauer scarp. It also implies that, contrary to the hypotheses of Rea [8] and Lonsdale [3], the Galapagos Rise played an insignificant role in the formation of the Bauer scarp, the present-day EPR axis, and the new transform faults.

\section{A new hypothesis}

Above we have presented three pieces of indirect evidence supporting the existence of a previously unrecognized spreading axis created following EPR reorganization at $\sim 20 \mathrm{Ma}$ : (1) The Galapagos Rise is situated too far east to account for the full span of lithosphere created between $\sim 20 \mathrm{Ma}$ and $\sim 8 \mathrm{Ma}$ without positing severe asymmetric spreading $(\sim 2$ or 3 to 1). Such asymmetries are not unheard of but are, nevertheless, rare. (2) The curved nature of the Galapagos Rise fracture zones to the east and the Garrett fracture zone to the west, which extend nearly to the Mendaña and Marquesas fracture zones, respectively, argue for the existence of a rotating microplate system with conjugate spreading axes originating soon after plate reorganization at $\sim 20$ Ma. (3) The difference in morphology between the Bauer and Anti-Bauer scarps suggests that the Bauer scarp represents a failed rift pseudofault.

The existence of an additional western spreading axis is a central feature of our new hypothesis for the Bauer ridge jump. The eastern Galapagos Rise spreading center is well preserved and appears to have originated by opening along the transform section of the Marquesas/Mendaña fracture zone complex. A linear disturbed zone lying between the Marquesas and Garrett fracture zones might indicate that the western rift of the Bauer Microplate also began as a feature subparallel to and in the vicinity of the Marquesas fracture zone.

Fig. 4 presents our hypothesis for the tectonic history of this region. Our aim here is not to formulate a precise reconstruction; the constraints, especially the magnetic anomaly data, are too few for that. Rather, we wish only to illustrate a possible sequence of events that might explain the structural interpretation of Fig. 3. We break the hypothesis into 7 developmental stages:

Stage 1: the EPR configuration prior to reorganization ( $\sim 20 \mathrm{Ma})$. This is probably a simplification because the Marquesas /Mendaña fracture zone complex appears to consist of multiple scarps.

Stage 2: plate boundary configuration following EPR reorganization. We hypothesize that the two ridges bounding the Bauer Microplate came into existence, in whole or in part, by opening of the transform sections of the Marquesas/Mendaña complex of fracture zones. There is reasonably compelling evidence for this origin of the Galapagos Rise but in the case of the western rift the evidence is less convincing. Due to the lack of reliable magnetic anomaly picks in the region, the sequence of events that lead to formation of the Bauer Microplate is impossible to determine for certain. One possibility is that both the Galapagos Rise and the western rift opened simultaneously on adjacent and nearby fracture zone scarps of the Marquesas/Mendaña complex. However, the likely location of the opening of the western rift is slightly south of the Marquesas fracture zone, which appears to preclude that scenario. Another possibility is that the Galapagos Rise formed immediately upon reorganization by opening along the Marquesas/Mendaña transform, but that the western rift formed a bit later, perhaps in response to the difficult spreading geometry of the Galapagos Rise with respect to the new spreading direction.

At its southern end the Galapagos Rise terminates at the Bauer fracture zone. We therefore assume that a Bauer transform acted as the southern boundary of the Bauer Microplate. Two significant transforms, the Garrett (probably a multiple transform complex) and an unnamed one between it and the Bauer fracture zone, appear to have existed on the west rift of the Bauer Microplate (Figs. 2 and 3). For simplicity, we use only the Garrett in our hypothesized 
reconstruction, as it appears to be the primary locus of initiation of Bauer scarp propagation.

Stage 3: continued spreading and enlargement of the Bauer Microplate, and initiation of the first stage of Bauer scarp ridge propagation. Propagation originates from the Garrett transform and stalls at the future location of the Wilkes transform. (We note that a small propagation event entered the Garrett from the south just prior to this propagation event, and may have had some influence on its timing.) The curvature of this pseudofault at its northern end suggests that a large overlapping spreading center was created between the propagating and failing rifts.

Stage 4: beginning of the second propagation stage. Just south of the Wilkes fracture zone, there are a series of curved lineaments within both the Anti-Bauer and Bauer scarp complexes, which were initiated immediately following the first propagation stage and formation of a possible large overlapper (above). It is difficult to envision the cause of these remarkable structures. Several suggestions were presented above to account for these structures (duelling propagation, close-set transform offsets and distributed shear), but none appear to explain completely the observed morphology. In Fig. 4 we present what we consider the most likcly of these possibilities: duelling propagation. However, we consider this matter unresolved. During the formation of these structures, another propagating rift be-gan moving northward from the Garrett transform.

Stage 5: rapid propagation of the second propagating rift to the northern end of the Bauer Microplate, creation of the Yaquina fracture zone, and continued slow propagation to the Gofar fracture zone. When the second propagating rift which emanated from the Garrett transform reached the presumed overlapping spreading center, it increased its propagation rate $\sim$ six-fold. This stage in rifting includes a right-stepping kink which may be related to formation of the Wilkes transform. The Yaquina transform fault is formed at the terminus of fast propagation; that is, at the Gallego fracture zone. Slow propagation continues north of the newly formed Yaquina, and at its cessation the Gofar transform is created.

Stage 6: continued propagation to the Quebrada transform and brief extension of Galapagos Rise spreading north of the Gallego transform. Ridge propagation north of the Gofar transform is shifted to the east, beginning within the Gofar transform itself. The Quebrada transform is formed at northernmost extent of this propagation. At this stage the Galapagos Rise briefly reorients before failure, creating a new transform which cross-cuts part of the Gallego fracture zone, and a new rift forms to the north.

Stage 7: cessation of spreading on the Galapagos Rise and continued spreading to current EPR configuration. The Bauer transform, which formed the southern boundary of the Bauer Microplate, ceased to exist when the Galapagos Rise ceased spreading.

\section{Conclusions}

In this paper we have examined the recently available high resolution satellite altimetry-derived gravity grid [19] for structural information relating to the formation of the Bauer scarp and Bauer Microplate. Our structural interpretation (Fig. 3) presents new and contradictory evidence to components of tectonic history hypotheses of Mammerickx et al. [6], Rea [8], and Lonsdale [3]:

1. without resorting to large spreading asymmetries $(\sim 2: 1$ to $3: 1)$ over the span of $\sim 10 \mathrm{Ma}$, the Galapagos Rise is situated too far east for it to have generated all the lithosphere created between plate reorganization $(\sim 20 \mathrm{Ma})$ and the Bauer scarp ( $\sim 8 \mathrm{Ma}$ ), as the hypothesis of Mammerickx et al. [6] predicts;

2. continuous fracture zones between the present-day EPR axis and the Galapagos Rise do not exist, as the hypothesis of Rea [8] predicts;

3. as evidenced by the eastward extension of the curved Galapagos Rise fracture zones into the Nazca Plate and the westward curved extension of the Garrett fracture zone into the Pacific Plate, the Bauer Microplate began soon after EPR reorganization at $\sim 20 \mathrm{Ma}$, not following the formation of the Bauer scarp as the hypothesis of Lonsdale [3] predicts.

The eastward location of the Galapagos Rise, the early existence of the Bauer Microplate, and the apparent inner- and outer-pseudofault nature of the Bauer and Anti-Bauer scarps, respectively, all imply the existence of a previously unrecognized spreading 
axis which existed to the west of the Galapagos Rise prior to formation of the Bauer scarps. We have formulated a new hypothesis for the tectonic history of this region (Fig. 4) with this additional spreading axis as a central component.

The Baner Microplate formed soon after the breakup of the Farallon Plate to form the present Cocos and Nazca plates. The two ridges bounding the microplate remained active for $>10$ m.y. The Galapagos Rise spreading center on its eastern boundary appears to have developed by opening along the transform section of the large right-stepping Marquesas/Mendaña fracture zonc complex. The western rift of the Bauer Microplate also appears to have formed subparallel to the Marquesas/Mendaña fracture zone complex.

The Bauer scarp ridge jump occurred by means of a propagating rift over most of its length, as the hypothesis of Lonsdale [3] predicts, although with the hypothesized western rift rather than the Galapagos Rise acting as the failing rift. Propagation proceeded in several stages. The first of two slow propagation events which emanated from the Garrett transform stalled at approximately the location of the future Wilkes transform. A second slow propagation event followed in the wake of the first and, upon reaching the complexities associated with an apparent overlap system which developed when the first propagator stalled, broke through very quickly to the Gallego fracture zone at the northern end of the Bauer Microplate. Propagation then proceeded slowly again to the Gofar transform, then shifted $100 \mathrm{~km}$ to the east and progressed northward again from within the newly formed Gofar transform. There is no obvious cause for this shift.

The formation of new transforms are clearly associated with the different stages in propagation. The Wilkes transformed formed where the first propagation event stalled, and also where the fast propagation event exhibited a right-stepping kink. The Yaquina transform formed at the boundary between fast and slow propagation, which also coincided with the location of the Gallego fracture zone at the northern boundary of the Bauer Microplate. The Gofar transform formed at the end of the next propagation event, and the Quebrada transform at the end of the final stage of propagation.

\section{Acknowledgements}

Our interest in the origin of the Bauer scarps and the development of the present southern EPR transforms was piqued by a study of the Wilkes transform and adjacent EPR supported by NSF Grants OCE 90-19741 and OCE 89-11376. However, the results reported here grew out of work undertaken in the preparation of a series of declined proposals to study ridge axis jumps and were not supported by any grant. Comments by Dick Hey, Roger Larson, and David Naar on an earlier draft led to substantial improvement of the final manuscript. UTIG contribution \#1221. LDEO contribution \#5480. [CL]

\section{References}

[1] D.S. Wilson, R.N. Hey and C. Nishimura, Propagation as a mechanism of ridge reorientation; A model for the tectonic evolution the Juan de Fuca Ridge, J. Geophys. Res. 89, 9215-9225, 1984.

[2] D.W. Caress, H.W. Menard and R.N. Hey, Eocene reorganization of the Pacific-Farallon spreading center north of the Mendocino Fracture Zone, J. Geophys. Res. 93, 2813-2838, 1988.

[3] P.F. Lonsdale, Segmentation of the Pacific-Nazca spreading center, $1^{\circ} \mathrm{N}-20^{\circ} \mathrm{S}$, J. Geophys. Res. 94, 12,197-12,225, 1989.

[4] J. Mammerickx, D.F. Naar and R.L. Tyce, The Mathematician paleoplate, J. Geophys. Res. 93, 3025-3040, 1988.

[5] J. Mammerickx and D. Sandwell, Rifting of old oceanic lithosphere, J. Geophys. Res. 91, 1975-1988, 1986.

[6] J. Mammerickx, E. Herron and L. Dorman, Evidence for two fossil spreading ridges in the southeast Pacific, Geol. Soc. Am. Bull. 91, 263-271, 1980.

[7] D.K. Rea, Analysis of a fast-spreading rise crest: The East Pacific Rise, $9^{\circ}$ to $12^{\circ}$ South. Mar. Geophys. Res. 2, 291-313, 1976.

[8] D.K. Rea. Tectonics of the Nazca-Pacific divergent plate boundary, in: Nazca Plate: Crustal Formation and Andean Convergence, L.D. Kulm, J. Dymond, E.J. Dasch and D.M. Hussong, eds., G.S.A. Mem. 154, 27-62, 1981.

[9] J. Campsie, G.L. Johnson, M.H. Rasmussen and J. Laursen, Dredged basalts from the western Nazca plate and the evolution of the East Pacific Rise, Earth Planet. Sci. Lett. 68, 271-285, 1984.

[10] J. Mammerickx, R.N. Anderson, H.W. Menard and S.M. Smith, Morphology and tectonic evolution of the east-central Pacific, Geol. Soc. Am. Bull. 86, I l1-118, 1975.

[11] D.W. Handschumacher, Post-Eocene plate tectonics of the eastern Pacific, in: The Geophysics of the Pacific Ocean Basin and its Margin, G.H. Sutton, M.H. Manghani and R. 
Moberly, eds., pp. 177-202, American Geophysical Union, Washington, D.C.. 1976.

[12] E.M. Herron, Sea-floor spreading and the Cenozoic history of the east-central Pacific, Geol. Soc. Am. Bull. 83, 16711692, 1972.

[13] S.F. Tebbins and S.C. Cande, Evolution of the South Pacific from the Early Oligocene to the Present, J. Geophys. Res., in press.

[14] S.F. Tebbins, S.C. Cande, L. Kovacs, J.C. Parra, J.L. $\mathrm{LaBrecque}$ and $\mathrm{H}$. Vergara, An aeromagnetic survey of the Chile Ridge. Part 1: A new tectonic map, J. Geophys. Res., in press.

[15] R.C. Searle, R.I. Rushy, J. Engeln, R.N. Hey, J. Zukin, P.M. Hunter, T.P. LaBas, H.J. Hoffman and R. Livermore, Comprehensive sonar imaging of the Easter microplate, Nature 341, 701-705, 1989.

[16] D.F. Naar and R.N. Hey, Tectonic evolution of the Easter microplate, J. Geophys. Res. 96, 7961-7993, 1991.

[17] S. Anderson-Fontana, J.F. Engeln, P. Lungren, R.L. Larson and S. Stein, Tectonics and evolution of the Juan Fernandez microplate at the Pacific-Nazca-Antarctic triple junction, J. Geophys. Res. 91, 2005-2018, 1986.

[18] R.L. Larson, R.C. Searle, M.C. Kleinrock, H. Schouten, R.T. Bird. D.F. Naar, R.I. Rusby, E.E. Hooft and H. Lasthiotakis, Roller-bearing tectonic evolution of the Juan Fernandez microplate, Nature 356, 571-576, 1992.

[19] D.T. Sandwell and W.H.F. Smith, Marine gravity anomalies from satellite altimetry, Version 7.2 (digital file available by anonymous ftp to baltica.ucsd.edu), 1995.

[20] R.N. Hey, M.C. Kleinrock, S.D. Miller, T.M. Atwater and R.C. Searle, SeaBeam/deep-tow investigation of an active oceanic propagating rift system. Galapagos $95.5^{\circ} \mathrm{W}, \mathrm{J}$. Geophys. Res. 91, 3369-3394, 1986.

[21] C. Small and D.T. Sandwell, Imaging mid-ocean ridge transitions with satellite gravity, Gcology 22, 123-126, 1994.

[22] M.T. Black and D.C. Macadoo, Spectral analysis of marine geoid heights and ocean depths, Mar. Geophys. Res. 10, $157-180,1988$

[23] S.C. Cande, J.L. LaBrecque, R.L. Larson, W.C. Pitman, X. Golovchenko, and W.F. Haxby, Magnetic Lineations of the World's Ocean Basins, American Association of Petroleum Geologists, Tulsa, 1989

[24] K.C. Macdonald, R.M. Haymon, S.P. Miller, J.C. Sempere and P.J. Fox, Deep-tow and Sea Beam studies of dueling propagating ridges on the East Pacific Rise near $20^{\circ} 40$ ' S, J. Geophys. Res. 93, 2875-2898, 1988.

[25] D.F. Naar, F. Martinez, R.N. Hey, T.B. Reed and S. Stein, Pito Rift: How a large-offset rift propagates, Mar. Geophys. Res. 13, 287-309, 1991.
[26] R.T. Bird and D.F. Naar, Intratransform origins of mid-ocean microplates. Geology 22, 987-990. 1994.

[27] D.G. Gallo, P.J. Fox, P. Lonsdale and J.A. Madsen, The morphotectonic expression of the world's fastest-slipping plate boundary: The Garrett transform, EOS Trans. Am. Geophys. Union 64, 855, 1983.

[28] D.J. Fornari, D.G. Gallo, M.H. Edwards, J.A. Madsen, M.R. Perfit and A.N. Shor, Structure and topography of the Siqueiros transform fault system: Evidence for the development of intra-transform spreading centers, Mar. Geophys. Res. 11, 263-299, 1989.

[29] J.R. Cochran. J.A. Goff, A. Malinverno, D.J. Fornari, C. Keeley and X. Wang, Morphology of a "superfast" mid-ocean ridge crest and flanks: The East Pacific Rise, $7^{\circ}-9^{\circ} \mathrm{S}$, Mar. Geophys. Res. 15, 65-75, 1993.

[30] M.C. Kleintock and R.N. Hey, Detailed tectonics near the tip of the Galapagos $95.5^{\circ} \mathrm{W}$ propagator: How the lithosphere tears and a spreading axis develops, J. Geophys. Res. 94, 13,801-13,838, 1989.

[31] D.S. Wilson, Kinematics of overlapping rift propagation with cyclic rift failure, Earth Planet. Sci. Lett. 96, 384-392, 1990.

[32] R. Hey, Tectonic evolution of the Cocos-Nazca spreading center, Geol. Soc. Am. Bull. 88, 1404-1420, 1977.

[33] P. Lonsdale and K.D. Klitgord, Structure and tectonic history of the eastern Panama Basin, Geol. Soc. Am. Bull. 89, 981-999, 1978.

[34] H. Schouten, K.D. Klitgord and D.G. Gallo, Edge-driven microplate kinematics, J. Geophys. Res. 98, 6689-6701, 1993.

[35] R.N. Hey, D.F. Naar, M.C. Kleinrock, J. Phipps Morgan, E. Morales and J.G. Schilling, Microplate tectonics along a superfast seafloor spreading system near Faster Island, Nature $317,320-324,1985$.

[36] J. Francheteau, P. Patriat, J. Segoufin, R. Armijo, M. Doucoure, A. Yelles-Chaouche, J. Zukin, D.F. Naar and R.C. Searle, Pito and Orongo fracture zones: northern and southern boundaries of the Easter microplate (southeast Pacific), Earth Planet. Sci. Lett. 89, 363-374, 1988.

[37] R.I. Rusby and R.C. Searle, Intraplate thrusting near the Easter microplate, EOS Trans. Am. Geophys. Union 72, 510, 1991.

[38] J.A. Goff, D.J. Fornari, J.R. Cochran, C. Keeley and A. Malinverno, The Wilkes transform system and "nannoplate". Geology 21, 623-626, 1993.

[39] R.N. Hey, P.D. Johnson, F. Martinez, J. Korenaga, M.L. Somers, Q.J. Huggett, T.P. LeBas, R.I. Rusby and D.F. Naar, Plate boundary reorganization at a large-offset, rapidly propagating rift, Nature 378, 167-170, 1995. 